OPEN ACCESS

Edited by:

Kezhen Qi,

Shenyang Normal University, China

Reviewed by:

Qingrui Zhang,

Yanshan University, China

Jiyang $L i$,

State Key Laboratory of Inorganic Synthesis and Preparative Chemistry,

Jilin University, China

*Correspondence:

Lu Han

hanlu@ustl.edu.cn

Specialty section: This article was submitted to Nanoscience,

a section of the journal

Frontiers in Chemistry

Received: 10 November 2019 Accepted: 18 December 2019

Published: 15 January 2020

Citation:

Zhang H, Wang Z, Luo X, LU J, Peng S, Wang Y and Han L (2020)

Constructing Hierarchical Porous

Carbons With Interconnected Micro-mesopores for Enhanced $\mathrm{CO}_{2}$ Adsorption. Front. Chem. 7:919. doi: 10.3389/fchem.2019.00919

\section{Constructing Hierarchical Porous Carbons With Interconnected Micro-mesopores for Enhanced $\mathrm{CO}_{2}$ Adsorption}

\author{
Hainan Zhang ${ }^{1}$, Zeming Wang ${ }^{2}$, Xudong Luo ${ }^{1}$, Jinlin Lu ${ }^{1}$, Shengnan Peng ${ }^{1}$, \\ Yongfei Wang ${ }^{1}$ and Lu Han ${ }^{1 *}$ \\ ${ }^{1}$ School of Materials and Metallurgy, University of Science and Technology Liaoning, Anshan, China, ${ }^{2}$ School of Chemical \\ and Processing Engineering, University of Leeds, Leeds, United Kingdom
}

A high cost-performance carbon dioxide sorbent based on hierarchical porous carbons (HPCs) was easily prepared by carbonization of raw sugar using commercially available nano- $\mathrm{CaCO}_{3}$ as a double-acting template. The effects of the initial composition and carbonization temperature on the micro-mesoporous structure and adsorption performance were examined. Also, the importance of post-activation behavior in the development of micropores and synthesis route for the formation of the interconnected micro-mesoporous structure were investigated. The results revealed excellent carbon dioxide uptake reaching up $2.84 \mathrm{mmol} / \mathrm{g}\left(25^{\circ} \mathrm{C}, 1 \mathrm{bar}\right)$, with micropore surface area of $786 \mathrm{~m}^{2} / \mathrm{g}$, micropore volume of $0.320 \mathrm{~cm}^{3} / \mathrm{g}$ and mesopore volume of $0.233 \mathrm{~cm}^{3} / \mathrm{g}$. We found that high carbon dioxide uptake was ascribed to the developed micropores and interconnected micro-mesoporous structure. As an expectation, the optimized HPCs offers a promising new support for the high selective capture of carbon dioxide in the future.

Keywords: hierarchical porous carbons, template method, micro-mesoporous structure, activation, carbon dioxide adsorption

\section{INTRODUCTION}

Carbon dioxide has gradually increased in the atmosphere over the past century, resulting in increasing concerns about the global warming and climate change (Kanki et al., 2016; Qi et al., 2017; Li et al., 2019). In order to reduce the carbon dioxide content in the air, people began to develop new energy, such as hydrogen energy (Qi et al., 2019), degradation of pollutants and sewage (Sun et al., 2018; Chen et al., 2019), among others, but fundamentally solve the problem of carbon dioxide pollution. However, although carbon dioxide is considered as the main greenhouse gas, it is a transformable carbon resource (Garbarino et al., 2014; Son et al., 2014; Pullar et al., 2019). In the presence of a suitable catalyst, the captured carbon dioxide molecules can be converted into synthetic natural gas, such as methane (Lavoie, 2014; Wang et al., 2016; Xia et al., 2019). Therefore, promoting the development of carbon dioxide capture and storage (CCS) has important social significance and great economic value (Han et al., 2012; Hayat et al., 2019).

Tremendous research has been devoted to the development of new technologies for CCS, especially those based on high-performance sorbents for carbon dioxide capture (Liang et al., 2004; Santis et al., 2016; Patel et al., 2017; Zhu et al., 2019). Novel solid sorbents capable of 
reversibly capturing carbon dioxide through dry adsorption process have many distinct advantages over wet absorption and adsorption-coupled membrane separation. These include low investment, the moderate energy cost for regeneration, and large capacity at room temperature (Yaumi et al., 2017). In the past decade, various types of solid sorbents have been attempted for CCS. Examples include zeolites (Megías-Sayago et al., 2019), modified porous silicas (Dassanayake et al., 2017), metal organic frameworks (MOFs) (Shi et al., 2019), calcium looping sorbents (Zhu et al., 2017), polymer membranes (Ahmad et al., 2016; Zhang et al., 2019), and nanoporous carbons (NCs) (Lee et al., 2014). In particular, MOFs and NCs have received much attention due to their excellent capture performance. However, MOFs are still not feasible economically and sensitive to water, resulting in failure due to structural damage.

On the other hand, NCs offer many promising applications as catalyst supports (Kim et al., 2005; Song et al., 2019), advanced electrodes (Liu et al., 2010; Xu et al., 2019), and energy-storage materials (Wu et al., 2009), among others. Various types of NCs showed promise as alternatives to carbon dioxide capture, such as modified activated carbons ( $\mathrm{Lu}$ et al., 2008), nitrogen-doped carbon molecular sieves (Patiño et al., 2014), and hierarchical porous carbons (HPCs) (Xia et al., 2014). These NCs presented several particular features like hydrophobic surface properties, superior thermal stability, and excellent chemical resistance, as well as some potential advantages in terms of extensive sources, tunable nano-pore structure, and controllable synthesis.

In view of the physical behavior during the adsorption process, the microporous structure was found more favorable for adsorption (Fan et al., 2013). Moreover, incorporation of basic groups into carbon framework, especially nitrogencontaining species doping was found highly praised in improving carbon dioxide selective adsorption performance (Wei et al., 2013). However, the realization of both micropore-enriched structures and nitrogen-doped modification depends heavily on the raw materials and synthesis route. For instance, Lu et al. reported the direct pyrolysis of copolymers based on resorcinol, formaldehyde, and lysine using the mannich reaction to fabricated nitrogen-doped porous carbon monolith (Hao et al., 2010). They measured high adsorption capacity reaching up $3.13 \mathrm{mmol} / \mathrm{g}$ at room temperature and 1 atm. Sun et al. reported a one-pot melting-assisted strategy using resorcinol and p-phthalaldehyde as carbon precursors, melamine as a nitrogen source, and Pluronic F127 as a surfactant under self-pressurized solvent-free conditions (Zhang et al., 2015). The resulting carbon material had a hierarchical porous structure with high surface area of $748 \mathrm{~m}^{2} / \mathrm{g}$, and exhibited excellent capacity of $2.73 \mathrm{mmol} / \mathrm{g}$ at $298 \mathrm{~K}$ and 1 bar.

From the standpoint of structural design, Qiu et al. synthesized a novel carbon sorbent with a special bimodal microporous structure (Li Y. et al., 2013). The carbonized porous aromatic framework (PAF-1) derivatives were formed by high-temperature $\mathrm{KOH}$ activation showed unexpectedly superior carbon dioxide capture capacity reaching up to $7.2 \mathrm{mmol} / \mathrm{g}$ at $273 \mathrm{~K}$ and 1 bar. However, the starting materials are seldom used and the synthesis route was complicated and cumbersome. To overcome these problems, Jaroniec et al. designed two different tailored routes to develop microporous and mesoporous carbon spheres to demonstrate that the site-occupying silica in carbon spheres works as hard templates for the large mesopores (Marszewska and Jaroniec, 2017). The resulting mesoporosity enabled faster transfer of carbon dioxide from the bulk to the micropores and effectively improved the diffusion process. The best sorbent showed carbon dioxide uptakes as high as $4.0 \mathrm{mmol} / \mathrm{g}\left(23^{\circ} \mathrm{C}, 1 \mathrm{bar}\right)$ and $7.8 \mathrm{mmol} / \mathrm{g}\left(0^{\circ} \mathrm{C}, 1 \mathrm{bar}\right)$. Despite the improvement in NCs, the main drawbacks related to cost and technology transfer to industrial applications remain to be solved when used for CCS. At present, the research mainly focuses on employing low-cost resources to develop efficient and economical synthesis routes for sorbents with ideal performances.

In this study, HPCs with abundant micropores were prepared using a simple and cost effective route. To optimize microporosity and mesoporosity of HPCs, several influencing factors based on the ratio of raw materials and carbonization temperature were investigated, and related synthesis mechanisms were examined. The resulting materials showed promising features toward CCS on a commercial scale.

\section{EXPERIMENTAL}

\section{Synthesis of HPCs}

The commercial nano- $\mathrm{CaCO}_{3}$ (ca. $40 \sim 60 \mathrm{~nm}$ in size from Chengdu Aike Reagent) served as a hard template and micropore producer. Raw sugar was used as the carbon precursor. HPCs were prepared by dispersing nano- $\mathrm{CaCO}_{3}$ in the raw sugar aqueous solution at the mass ratios of raw sugar to $\mathrm{CaCO}_{3}$ varying from 2:8 to 5:5. The resulting homogeneous solution was then left to evaporated and dried in a water bath at $85^{\circ} \mathrm{C}$. The collected semi-dry powders were dried thoroughly and then kept at 700 or $900^{\circ} \mathrm{C}$ for $2 \mathrm{~h}$ under flowing nitrogen (99.999\%). The carbonized mixture was treated with $2 \mathrm{M} \mathrm{HCl}$ solution and then washed several times with distilled water, resulting in a solid product after drying overnight at $100^{\circ} \mathrm{C}$. For comparison, a tentative sample was also obtained via post-activation method for $\mathrm{HPCs}$ at $700^{\circ} \mathrm{C}$ for $1 \mathrm{~h}$ under flowing carbon dioxide $\left(50 \mathrm{~cm}^{3} / \mathrm{min}\right)$. The as-made carbon materials were labeled as HPCs ${ }^{*}-x-y$, where the superscript $*$ represents the activated sample, and lowercase $x$ and $y$ are the share of raw sugar in dried raw materials and carbonization temperature, respectively.

\section{Characterization and Evaluation of HPCs}

Thermogravimetric (TG) analysis was carried out using a thermal analysis system (STA 449/F3, Netzsch) with heating rate of $10^{\circ} \mathrm{C} / \mathrm{min}$ under nitrogen flow. The carbon yield of HPCs samples was calculated from the weight of resultant carbons divided by the weight of dried raw materials. Xray powder diffraction (XRD) pattern was measured on a diffractometer (Bruker D8 ADVANCE) with a scanning rate of $2^{\circ} / \mathrm{min}$, using $\mathrm{Cu} \mathrm{K} \alpha$ radiation. The microstructure of samples were observed by field emission scanning electron microscopy (FESEM, Carl Zeiss, Supra 40). The structures and morphologies of the activated sample were characterized by transmission electron microscopy (TEM) (JEM-2100F JEOL, $200 \mathrm{kV}$ ). The 
microporosity and mesoporosity properties of samples were analyzed by the nitrogen adsorption-desorption isotherms at $-196^{\circ} \mathrm{C}$ (Micrometrics, ASAP 3020). Specific surface areas of samples were determined using the Brunauer-Emmett-Teller (BET) equation. The total pore volume was calculated from the nitrogen adsorption amount at the relative pressure of 0.995 . The mesoporous volumes of samples were determined using the Barrett-Joyner-Halanda (BJH) method. The micropore area and volume were estimated by the t-plot method (Brunauer et al., 1938). The pore size distributions were derived from the adsorption branch of nitrogen isotherms using the $\mathrm{BJH}$ method (Sing, 1985). The carbon dioxide adsorption performance of the sample was measured at 25 and $0^{\circ} \mathrm{C}$ using a carbon dioxide adsorption instrument (JWGB, JW-BK112). Prior to adsorption measurement, all samples were degassed at $200^{\circ} \mathrm{C}$ for $12 \mathrm{~h}$.

\section{RESULTS AND DISCUSSION}

\section{TG Analysis}

The carbonization process of raw sugar- $\mathrm{CaCO}_{3}$ mixtures was studied by TG analysis in the temperature range from 25 to $1,000^{\circ} \mathrm{C}$ under nitrogen flow, and the results are shown in Figure 1. The decomposition temperature of nano- $\mathrm{CaCO}_{3}$ was estimated to about $660^{\circ} \mathrm{C}$, and carbonization of pure raw sugar occurred at around $200^{\circ} \mathrm{C}$ with a carbon yield of ca. $19 \%$ at $900^{\circ} \mathrm{C}$. Compared to pure raw sugar, the decomposition of the mixture was delayed from 300 to $660^{\circ} \mathrm{C}$. This was attributed to incorporated nano- $\mathrm{CaCO}_{3}$ in the matrix. Above $660^{\circ} \mathrm{C}$, the weight loss dropped rapidly, indicating that carbon consumption process occurred above $660^{\circ} \mathrm{C}$. Since the decomposition of $\mathrm{CaCO}_{3}$ into $\mathrm{CaO}$ and carbon dioxide above this temperature, it can be concluded that carbon dioxide gas reacted with carbon walls, leading to its oxidation into $\mathrm{CO}$ and removal. This etching process was known as "inner-activation" effect, which was first detected in the carbonization process of PF (phenol formaldehyde) resin and $\mathrm{CaCO}_{3}$ composite (Zhao et al., 2010). To investigate the porous texture of the prepared carbons, two series were prepared by changing the carbonization temperature: HPCs- $x$-700 series $\left(x=2,3,4\right.$, and 5) carbonized at $700^{\circ} \mathrm{C}$ as the initial stage of etching reaction and HPCs- $x-900$ series $(x$ $=2,3,4$, and 5) carbonized at $900^{\circ} \mathrm{C}$ as the mature stage of etching reaction.

The carbon yield of both HPCs- $x-700$ and HPCs- $x-900$ series $(x=2,3,4$, and 5) as a function of the mass ratio of raw sugar: $\mathrm{CaCO}_{3}$ is shown in Figure 2. Now that carbon dioxide occurred above $700^{\circ} \mathrm{C}$, adequate carbon dioxide might consume more carbon according to the reaction: $\mathrm{CO}_{2}+\mathrm{C} \rightarrow 2 \mathrm{CO}$ (Zhao et al., 2010). Figure 2 confirmed this assumption, showing that both series with a total of eight samples consumed carbon according to the above reaction. At the same initial composition, more carbon dioxide were produced as carbonization temperature rose. Thus, the carbon consumption of HPCs- $x-900$ series was higher than that of HPCs- $x$-700 series. At the same carbonization temperature, the carbon consumption gradually decreased as $\mathrm{CaCO}_{3}$ ratio in the mixture reduced. Thus, an increase in carbon yield was linked to the decrease of carbon dioxide emissions. The effect of carbon dioxide post-activation on porous texture of various carbons

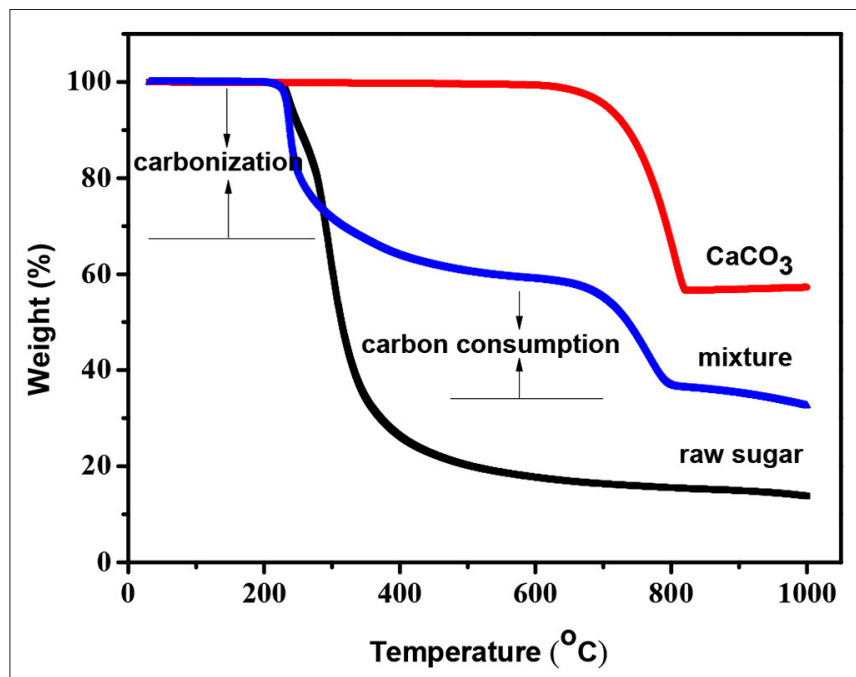

FIGURE 1 | TG curves of raw sugar, nano- $\mathrm{CaCO}_{3}$, and raw sugar- $\mathrm{CaCO}_{3}$ mixture (ratio of raw sugar: $\mathrm{CaCO}_{3}=5: 5$ ) under nitrogen flow.

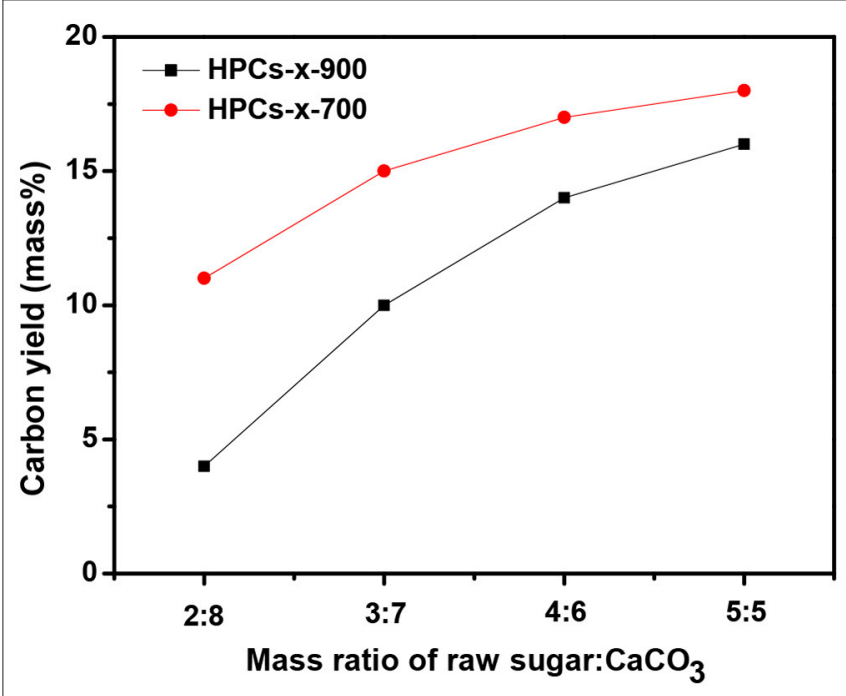

FIGURE 2 | Carbon yield of HPCs- $x-900$ and HPCs- $x-700$ samples as a function of the mass ratio of raw sugar: $\mathrm{CaCO}_{3}$.

had been studied thoroughly (Liou, 2010; Li Y. et al., 2013; Wickramaratne and Jaroniec, 2013a), and the effect of inneractivation on microstructure of HPCs materials needs further investigation as well.

\section{XRD Patterns}

Typical XRD pattern was exhibited in Figure 3 to verify the graphitic characteristics of carbon. A sharp diffraction peak located at $2 \theta \approx 23^{\circ}$ and a broad diffraction peak located at $2 \theta \approx$ $44^{\circ}$ were clearly identified, indexed to the (002) reflection of pure graphitic lattice and the (100) reflection of the graphitic carbon, respectively (Xu et al., 2011). This structure might be beneficial to enhance catalytic effect for carbon dioxide conversion when the carbon combines with active materials (Wang et al., 2016). 


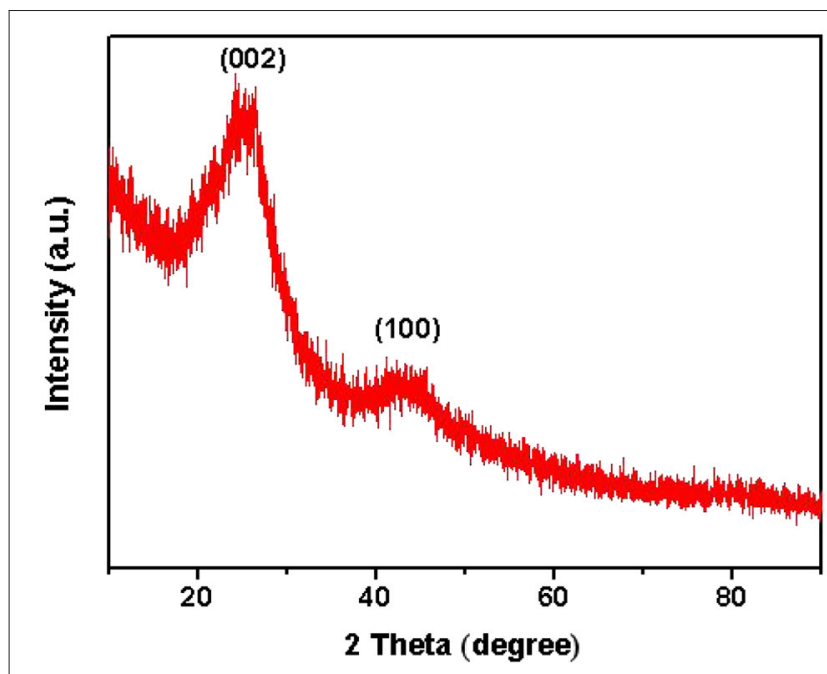

FIGURE 3 | XRD pattern of HPCs-5-900.

\section{FESEM Images}

The morphological evolution from raw sugar- $\mathrm{CaCO}_{3}$ physical mixture into HPCs was depicted in Figure 4, using a series of FESEM images $(a \sim f)$. In Figures $4 \mathbf{a}, \mathbf{b}$, the pristine raw sugar displayed a dense structure filled with apparent inclusions, corresponding to the nano- $\mathrm{CaCO}_{3}$ particles with their aggregates shown in the inset of Figure 4a. After high temperature carbonization above $700^{\circ} \mathrm{C}$, the raw sugar was converted into graphitic carbon as demonstrated by $\mathrm{TG}$ and $\mathrm{XRD}$, and the nano- $\mathrm{CaCO}_{3}$ decomposed into nano- $\mathrm{CaO}$ and carbon dioxide as confirmed by TG. As shown in Figures $\mathbf{4 c}$,d, the as-received product depicted highly porous structure rich with fine pores, retaining no memory of pristine raw sugar- $\mathrm{CaCO}_{3}$ structure. After removal of $\mathrm{CaO}$ fillers, largely interconnected mesopores of $20 \sim 100 \mathrm{~nm}$ in diameter were formed in the carbon matrix, which were different from the morphology of matrix embedded with nano- $\mathrm{CaO}$ particles.

\section{TEM Images}

To further investigate the microstructure of microporeenriched HPCs after activation with carbon dioxide gas, a typical HPCs*-5-900 sample was characterized by TEM. As shown in Figures 5a,b, the edges at high magnification displayed well-developed three-dimensional system of the interconnected pores built by random carbon walls $<10 \mathrm{~nm}$ in thickness to produce loose nanostructures. In Figures $\mathbf{5 c}$,d, the magnified TEM image of the circular region by white circles in Figure 5a. The pore region was detected by the reaction of dilute hydrochloric acid solution with site-occupying template. The inwall of carbon was rough and curly, implying the structural disintegration of carbon and existence of fine micropores. The external carbon structure illustrated a dendritic arrangement with abundant micropores, suggesting the successful activation resulting from extrinsic carbon dioxide against carbon.

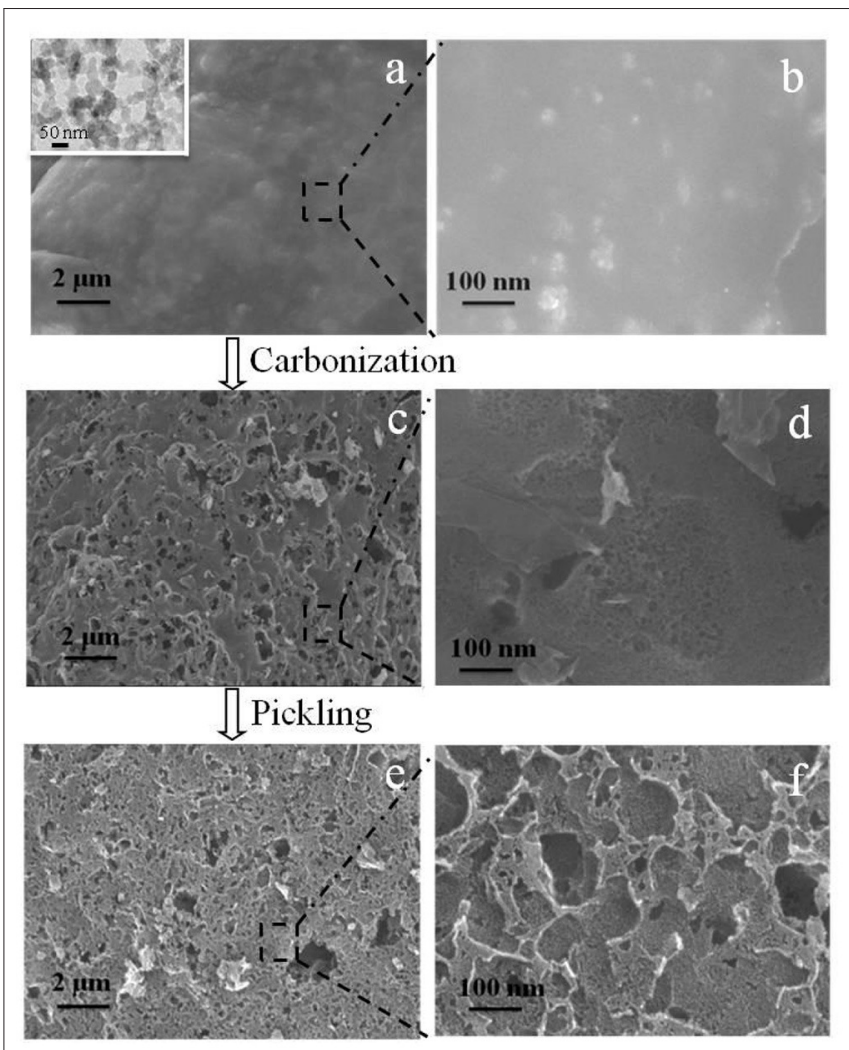

FIGURE 4 | FESEM images of (a) and (b) raw sugar- $\mathrm{CaCO}_{3}$ mixture matrix (inset of (a) is the TEM image of nano- $\mathrm{CaCO}_{3}$ particles), (c,d) carbonized matrix embedded with templates, and (e,f) HPCs.

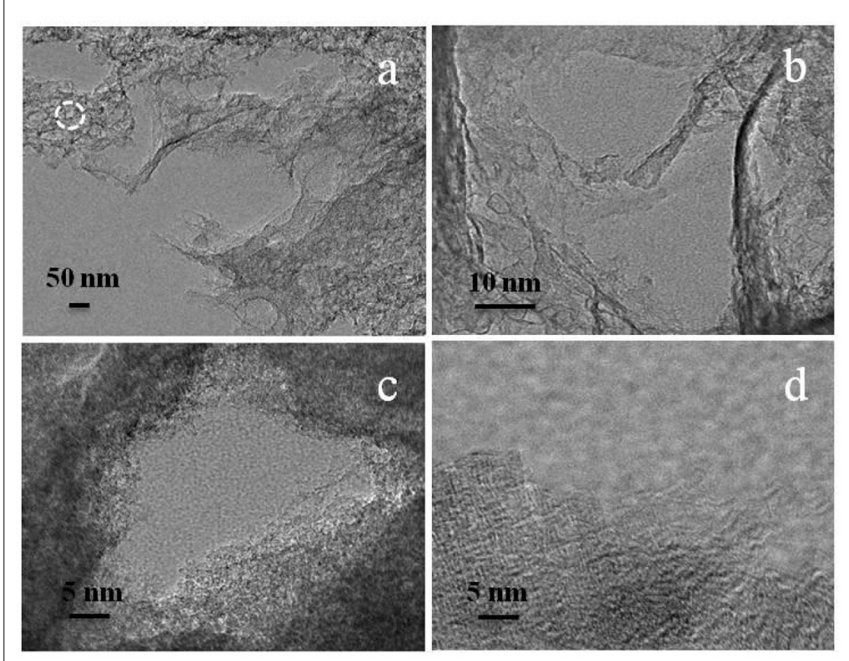

FIGURE 5 | TEM images of HPCs ${ }^{\star}-5-900$ showing: (a) edges of carbon, (b) randomly carbon walls, (c) site-occupying region, and (d) micropore-enriched edges after carbon dioxide gas activation.

\section{Nitrogen Adsorption/Desorption Isotherms}

In Figures 6A,B, the nitrogen adsorption/desorption isotherms of HPCs- $x$-700 and HPCs- $x$-900 series $(x=2,3,4$, and $5)$, respectively. The nitrogen adsorption/desorption isotherms 
A

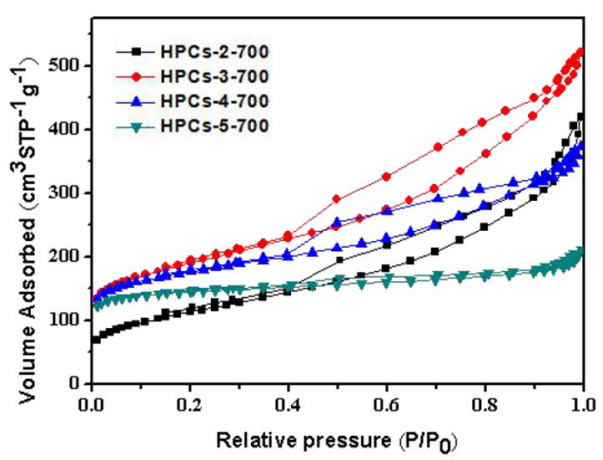

B

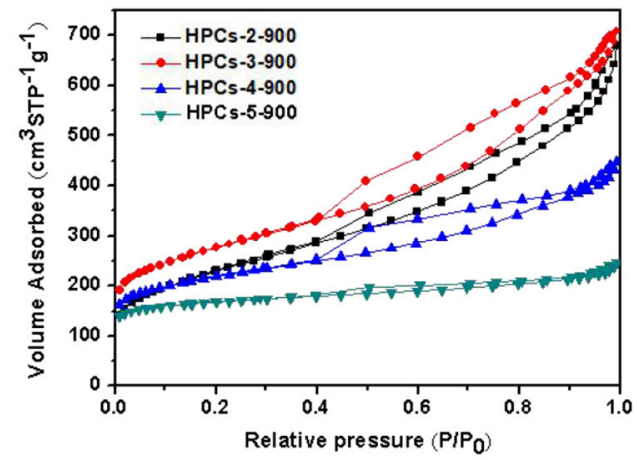

FIGURE 6 | Nitrogen adsorption/desorption isotherms of HPCs samples carbonized under nitrogen at (A) $700^{\circ} \mathrm{C}$ and $(\mathbf{B}) 900^{\circ} \mathrm{C}$ for $2 \mathrm{~h}$.

of two series were typical Langmuir IV curves with distinct hysteresis loops, indicating the presence of mesopores created by the removal of site-occupying $\mathrm{CaCO}_{3}$ or $\mathrm{CaO}$. The significant increase of adsorption volume at low-pressure range $\left(\mathrm{P} / \mathrm{P}_{0}<\right.$ 0.1 ) indicated the existence of abundant micropores. Three imaginable and reasonable sources caused the micropores to form: the voids derived from high-temperature pyrolysis of raw sugar, carbon dioxide escape routes during $\mathrm{CaCO}_{3}$ decomposition, and fine etching pores in carbon wall. Although there is no adsorption hysteresis in the macropore range ( $>$ $300 \mathrm{~nm}$ ), the existence of micron level voids in the carbon matrix was clearly confirmed in the preceding FESEM images. Thus, it could be suggested that the formation of voids was mainly attributed to leaching of the aggregates of template particles (Li T. et al., 2013).

Table 1 lists the calculated adsorption parameters for both series carbonized at 700 and $900^{\circ} \mathrm{C}$, respectively. All HPCs samples showed high surface areas ranging from 408 to $986 \mathrm{~m}^{2} / \mathrm{g}$ and large total pore volumes varying from 0.327 to $1.095 \mathrm{~cm}^{3} / \mathrm{g}$. For HPCs- $x$-700 or HPCs- $x$ - 900 series $(x=2$, 3,4 , and 5), as $x$ increased, $\mathrm{V}_{\text {meso }}$ decreased gradually but $\mathrm{V}_{\text {micro }}, \mathrm{V}_{\text {micro }} / \mathrm{V}_{\text {total }}, \mathrm{S}_{\mathrm{BET}-\text { micro, }}$ and $\mathrm{S}_{\mathrm{BET}-\text { micro }} / \mathrm{S}_{\mathrm{BET}}$ rose gradually. This indicated a regular transition from mesoporosity to microporosity when mass ratio of raw sugar/CaCO 3 increased. The former was attributed to the decrease in the amount of site-occupying $\mathrm{CaCO}_{3}$. For each HPCs series, both micropore volume and surface area increased as raw sugar ratio rose. As suggested by Figure 2, carbon yield rose as raw sugar ratio increased, in accordance with the changed trend of micropore volume and surface area. The inneractivation effect of carbon dioxide on the carbon matrix had also been confirmed by the previous discussion. The etching effect was greatly determined by respective content and dependency state of carbon dioxide and carbon, according to the reaction: $\mathrm{CO}_{2}+\mathrm{C} \rightarrow 2 \mathrm{CO}$. Thus, it can be concluded that the development of micropores did not only depend on carbon dioxide discharge derived from inner-activation but also closely associated with the essential amount of carbon matrix. Note that data presented here were slightly different from those reported in previous research (Zhao et al., 2010),
TABLE 1 | Textural properties of all related HPCs samples.

\begin{tabular}{lccccc}
\hline Sample & $\begin{array}{c}\mathbf{S}_{\text {BET }}\left(\mathbf{S}_{\text {BET-mi }}^{\mathbf{a}}\right) \\
\left(\mathbf{m}^{\mathbf{2}} \mathbf{g}\right)\end{array}$ & $\mathbf{S}_{\text {BET-mi }} / \mathbf{S}_{\text {BET }}$ & $\begin{array}{c}\mathbf{V}_{\mathbf{t}}\left(\mathbf{V}_{\mathbf{m}}^{\mathbf{b}}\right) \\
\left(\mathbf{c m}^{\mathbf{3}} \mathbf{g}\right)\end{array}$ & $\mathbf{V}_{\mathbf{m e}}^{\mathbf{c}}$ & $\mathbf{V}_{\mathbf{m i}} / \mathbf{V}_{\mathbf{t}}$ \\
\hline HPCs-2-700 & $408(59)$ & 0.145 & $0.650(0.024)$ & 0.626 & 0.037 \\
HPCs-3-700 & $684(252)$ & 0.368 & $0.714(0.107)$ & 0.607 & 0.149 \\
HPCs-4-700 & $646(375)$ & 0.580 & $0.578(0.156)$ & 0.422 & 0.270 \\
HPCs-5-700 & $562(491)$ & 0.874 & $0.327(0.195)$ & 0.132 & 0.596 \\
HPCs-2-900 & $822(231)$ & 0.281 & $1.052(0.100)$ & 0.952 & 0.095 \\
HPCs-3-900 & $986(383)$ & 0.388 & $1.095(0.165)$ & 0.930 & 0.151 \\
HPCs-4-900 & $793(457)$ & 0.576 & $0.693(0.193)$ & 0.500 & 0.278 \\
HPCs-5-900 & $638(532)$ & 0.834 & $0.382(0.215)$ & 0.167 & 0.563 \\
HPCs -5-900 & $936(786)$ & 0.840 & $0.553(0.320)$ & 0.233 & 0.579 \\
\hline
\end{tabular}

${ }^{a}$ The micropore surface area was estimated using the t-plot method. ${ }^{b}$ The micropore volume was estimated using the t-plot method. ${ }^{c}$ The mesopore volume was estimated by BJH method.

and could be attributed to differences in the carbon source. In fact, the carbon source used in previous studies was phenolic resin. The effect of other carbon sources, such as resorcinol-formaldehyde mixture, sucrose, phenolic resin and polyacrylonitrile on porous texture will be reported in future publications.

Moreover, the HPCs- $x-900$ series exhibited higher $\mathrm{S}_{\mathrm{BET}}$, $\mathrm{S}_{\mathrm{BET}-\text { micro, }}$ and $\mathrm{V}_{\text {micro }}$ than those samples with the same raw materials ratio carbonized at $700^{\circ} \mathrm{C}$, but the carbon yield of HPCs- $x$-700 series was higher than that of the carbonized samples at $900^{\circ} \mathrm{C}$. This demonstrated that carbonization at $900^{\circ} \mathrm{C}$ could ensure the complete decomposition of $\mathrm{CaCO}_{3}$, and samples were thoroughly activated. In addition, the gap in amount of micropores between every two samples with the same raw materials ratio but carbonized at 900 and $700^{\circ} \mathrm{C}$, respectively, became narrow due to the weakening of carbon dioxide inneractivation effect with decrease in amount of $\mathrm{CaCO}_{3}$. Specifically, the difference in micropore volume between HPCs-2-900 and HPCs-2-700 was estimated to $0.076 \mathrm{~cm}^{3} / \mathrm{g}$. However, these values decreased to $0.058,0.037$ and $0.020 \mathrm{~cm}^{3} / \mathrm{g}$, respectively, as the value of $x$ rose from 3 to 5 . Also, $\mathrm{S}_{\mathrm{BET}-\mathrm{mi}} / \mathrm{S}_{\mathrm{BET}}$ and $\mathrm{V}_{\mathrm{mi}} / \mathrm{V}_{\mathrm{t}}$ increased to 0.834 and 0.563 , respectively, as the value of $x$ rose 
to 5 . The microporosity structure was more prominent, especially for HPCs-5-700 and HPCs-5-900 samples.

To develop large volumes of small micropores for high carbon dioxide uptakes, the carbon dioxide activation was performed on HPCs-5-900 at $700^{\circ} \mathrm{C}$ for $1 \mathrm{~h}$ under flowing carbon dioxide. Figure 7A shows the nitrogen adsorption/desorption isotherms of HPCs-5-900 and HPCs* ${ }^{*}$-900 samples. HPCs* ${ }^{*}-5-900$ illustrated Langmuir IV type curves with distinct hysteresis loop, indicating the presence of constricted mesopores, similar to that of HPCs-5-900 sample. As expected, the nitrogen adsorption amount of HPCs*-5-900 in the low-pressure range $(<0.1)$ was significantly higher than that of HPCs-5-900 because the former was activated by carbon dioxide and its micropore volume is enlarged by almost $50 \%$. The pore size
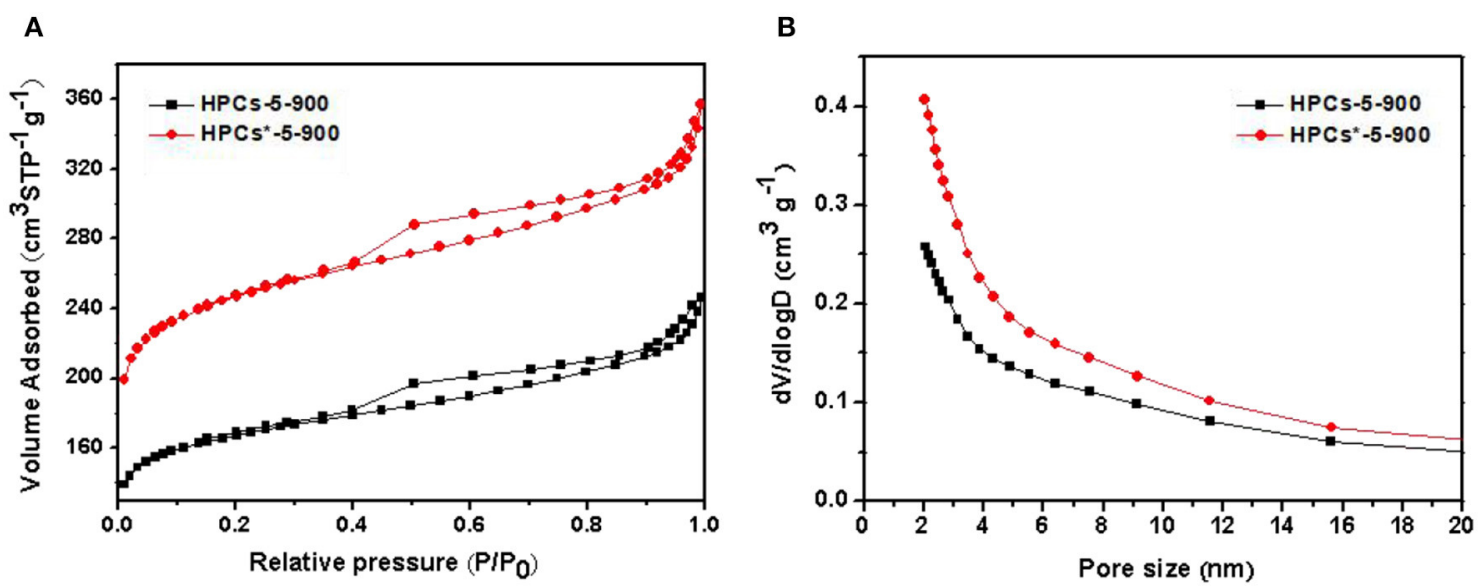

FIGURE 7 | (A) Nitrogen adsorption/desorption isotherms of HPCs-5-900 and HPCs*-5-900. (B) The corresponding pore size distributions curves calculated by BJH method.
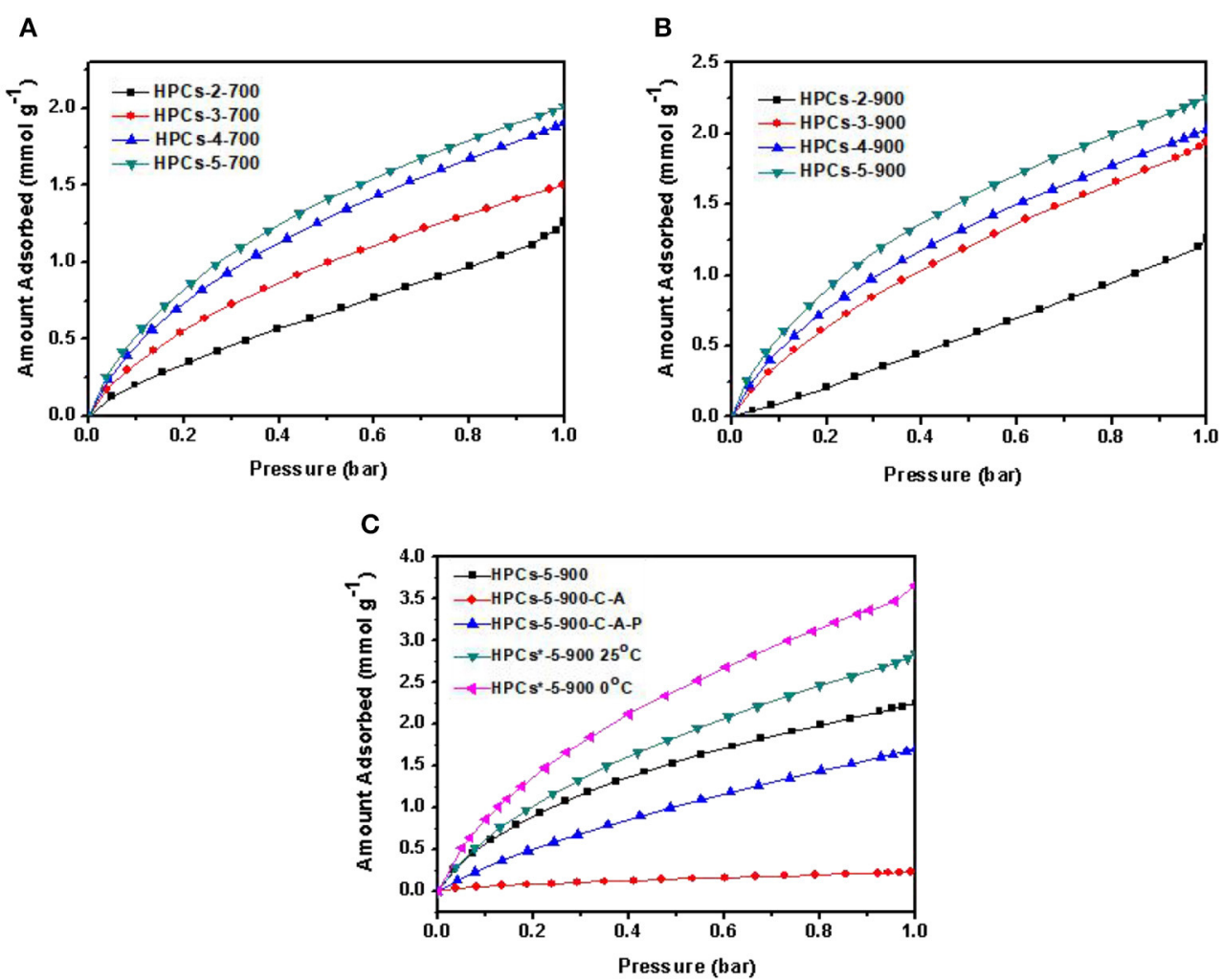

FIGURE 8 | Carbon dioxide adsorption isotherms measured at $25^{\circ} \mathrm{C}$ for HPCs series carbonized at (A) $700^{\circ} \mathrm{C}$ and (B) $900^{\circ} \mathrm{C}$. (C) Carbon dioxide adsorption isotherms measured for a series of HPCs-5-900 samples obtained by different routes. 
distributions of HPCs-5-900 and HPCs*-5-900 samples obtained by $\mathrm{BJH}$ method are inserted in Figure $7 \mathbf{B}$. It clearly suggested that the amount of micropores in the activated sample was superior to that of the unactivated sample, demonstrating the benefits of carbon dioxide post-activation. On the other hand, a slight increase in the mesopore volume was carefully observed from the hysteresis loop and the data listed in Table 1. The development of mesopores was also caused by carbon dioxide activation that widened all pores existed in HPCs samples or produced new pores in the carbon matrix. In other words, a part of micropores connected to become mesopores or newborn mesopores directly germinated in the carbon matrix when carbon dioxide etching reaction occurred (Li T. et al., 2013; Marszewska and Jaroniec, 2017).

\section{Carbon Dioxide Adsorption Isotherms}

The carbon dioxide adsorption isotherms of HPCs- $x-700$ and HPCs- $x-900$ series at $25^{\circ} \mathrm{C}$ are shown in Figures $8 \mathbf{A}, \mathbf{B}$, respectively. HPCs-5-900 showed the best performance toward carbon dioxide adsorption and the maximum value of adsorption capacity was estimated to $2.25 \mathrm{mmol} / \mathrm{g}$ at $25^{\circ} \mathrm{C}$ and 1 bar. Although HPCs-3-900 depicted the highest total pore volume of $1.095 \mathrm{~cm}^{3} / \mathrm{g}$ and mesopore volume of $0.930 \mathrm{~cm}^{3} / \mathrm{g}$ (Table 1), HPCs-5-900 possessed a superior micropore volume of $0.215 \mathrm{~cm}^{3} / \mathrm{g}$, occupying $\sim 56 \%$ of total pore volume. Hence, it can be concluded that the highest carbon dioxide adsorption performance of HPCs-5-900 necessarily originated from its huge amount of micropore volume. Despite using fillers, such as $\mathrm{SiO}_{2}$ (Feng et al., 2014; Marszewska and Jaroniec, 2017), MgO (Meng and Park, 2012) and porous concrete (Günther et al., 2012) in the preparation of porous carbon materials, nano- $\mathrm{CaCO}_{3}$ particles showed preferable advantages over other oxide fillers for hierarchical porous structure because they served simultaneously as mesopore templates and micropore producers (Zhao et al., 2010; Liu et al., 2013). The decomposition products of nano- $\mathrm{CaCO}_{3}$ particles results in nano-sized $\mathrm{CaO}$ particles and carbon dioxide gas, responsible for the formation of mesopores and micropores in carbon matrix, respectively. Thus, a series of HPCs with varying degrees of microporosity and mesoporosity can easily be obtained by adjusting the ratio of raw sugar/ $\mathrm{CaCO}_{3}$ and carbonization temperature. From an economic standpoint, the mass ratio of raw sugar $/ \mathrm{CaCO}_{3}$ as $1: 1$ is favorable. Besides, development of microporosity for carbon dioxide adsorption by setting the carbonization temperature at $900^{\circ} \mathrm{C}$ is desirable.

The chemical adsorption of carbon dioxide on HPCs materials is almost impossible due to the absence of basic groups like nitrogen-containing species in carbon. Since HPCs* ${ }^{*}-5-900$ possessed a typical hierarchical porous structure with ultrahigh micropores and moderate mesopores, and also exhibited a superior carbon dioxide uptake, it clearly demonstrated that the physical uptake was closely related to this micro-mesoporous structure. The importance of mesopores in carbon dioxide capture was recently reported (Wickramaratne and Jaroniec, 2013a,b; Marszewska and Jaroniec, 2017). In the case of HPCs materials, the synthetic route was adjusted in this study to deduce the necessity of mesopores in micropore-enriched carbon. As shown in Figure 8C, compared to HPCs-5-900, the sample obtained by preliminary carbonization, subsequent activation and final pickling (labeled as HPCs-5-900-C-A-P) exhibited a smaller carbon dioxide uptake of $1.69 \mathrm{mmol} / \mathrm{g}\left(25{ }^{\circ} \mathrm{C}, 1 \mathrm{bar}\right)$. Specifically, the carbon dioxide uptake of HPCs-5-900-C-A (carbonized and activated without the pickling process) just reached to $0.17 \mathrm{mmol} / \mathrm{g}$ at $25^{\circ} \mathrm{C}$ and 1 bar. The $\mathrm{CO}_{2}$ adsorption properties of the prepared all related HPCs samples are shown in Table 2.

The essential difference from HPCs-5-900, which was just the process order, would definitively affect the carbon dioxide adsorption performance. The presence of site-occupying $\mathrm{CaO}$ particles in carbon matrix caused two negative effects on carbon dioxide diffusion. One was related to the post-activation effect and the other was linked to the development of interconnected micro-mesoporous structure. The presence of template particles blocked activation gas diffusion from the bulk phase to the interior, resulting in delayed pore-creating reaction. For HPCs-5-900-C-A, the almost negligible carbon dioxide uptake resulted from both effects. In the case of HPCs-5-900-C-A$\mathrm{P}$, the removal of these particles during the last step resulted in interconnected micro-mesoporous structure and improved carbon dioxide diffusion from the bulk phase to micropores. Therefore, the carbon dioxide uptake increased dramatically compared to HPCs-5-900-C-A, but still lower than HPCs-5-900. Thus, the removal of site-occupying templates before carbon dioxide activation was beneficial for activation gas transfer in unobstructed path and played a significant role in improving the microporous textures. The obtained hierarchical porous structure was very important in improving the carbon dioxide uptake. In addition, as shown in Table 3, we compared the texture properties of samples in this work with the carbon samples of different structures reported in the previous literature.

\section{CONCLUSIONS}

In this study, a series of high-quality and cost-effective carbon dioxide sorbents based on HPCs are successfully synthesized by carbonizing raw sugar- $\mathrm{CaCO}_{3}$ composite precursors. Both

TABLE $2 \mid \mathrm{CO}_{2}$ adsorption properties of all related HPCs samples.

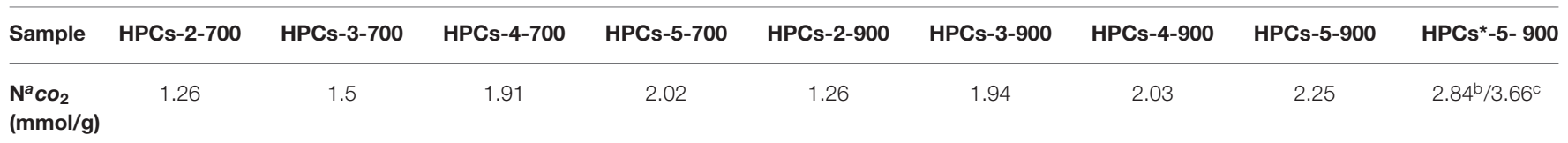

a The carbon dioxide uptake at $25^{\circ} \mathrm{C}$ and 1 bar. ${ }^{b, c}$ The carbon dioxide adsorption performance was measured at 25 and $0^{\circ} \mathrm{C}$, respectively. 
TABLE 3 | The comparison of textural properties of samples in this work with the literature values.

\begin{tabular}{|c|c|c|c|c|c|c|}
\hline Carbon structure & $\mathbf{T}\left({ }^{\circ} \mathbf{C}\right)$ & $\begin{array}{c}S_{B E T} \\
\left(\mathrm{~m}^{2} / g\right)\end{array}$ & $V_{t}\left(\mathrm{~cm}^{3} / \mathrm{g}\right)$ & $V_{m i}\left(\mathrm{~cm}^{3} / \mathrm{g}\right)$ & $\begin{array}{c}\mathrm{N}_{\mathrm{Co}_{2}} \\
\text { (mmol/g) } \\
\text { (Condition) }\end{array}$ & References \\
\hline Hierarchical porous carbons & $900^{\circ} \mathrm{C}$ & 936 & 0.553 & 0.32 & $\begin{array}{c}2.84 \\
\left(25^{\circ} \mathrm{C} 1 \text { bar }\right)\end{array}$ & This work \\
\hline Hierarchical macroporous nitrogen-doped carbons & $600^{\circ} \mathrm{C}$ & 682.8 & - & - & $\begin{array}{c}2.69 \\
\left(25^{\circ} \mathrm{C} 1 \text { bar }\right)\end{array}$ & Li et al., 2016 \\
\hline Hierarchical porous graphene-based carbons & $850^{\circ} \mathrm{C}$ & 459 & 1.17 & 0.11 & $\begin{array}{c}1.76 \\
\left(0^{\circ} \mathrm{C} 1 \text { bar }\right)\end{array}$ & Xia et al., 2014 \\
\hline Ordered mesoporous carbon & $850^{\circ} \mathrm{C}$ & 1400 & 1.02 & 0.42 & $\begin{array}{c}2.64 \\
\left(25^{\circ} \mathrm{C} 1 \text { bar }\right)\end{array}$ & Mahurin et al., 2014 \\
\hline Nitrogen-doped microporous carbons & $800^{\circ} \mathrm{C}$ & 2567 & 1.49 & 1.25 & $\begin{array}{c}2.78 \\
\left(25^{\circ} \mathrm{C} 1 \text { bar }\right)\end{array}$ & Fan et al., 2013 \\
\hline Nitrogen-doped mesoporous carbons & $600^{\circ} \mathrm{C}$ & 537 & 0.47 & 0.17 & $\begin{array}{c}2.8 \\
\left(25^{\circ} \mathrm{C} 1 \text { bar }\right)\end{array}$ & Wei et al., 2013 \\
\hline Mesoporous carbon & $900^{\circ} \mathrm{C}$ & 3325 & 2.25 & 0.98 & $\begin{array}{c}2.4 \\
\left(25^{\circ} \mathrm{C} 1 \text { bar }\right)\end{array}$ & Huang et al., 2016 \\
\hline Mesoporous carbon & $800^{\circ} \mathrm{C}$ & 974 & 1.93 & 0.1 & $\begin{array}{c}2.41 \\
\left(25^{\circ} \mathrm{C} 1 \text { bar }\right)\end{array}$ & Lee et al., 2014 \\
\hline Mesoporous carbon & $800^{\circ} \mathrm{C}$ & 748 & 0.49 & 0.23 & $\begin{array}{c}2.73 \\
\left(25^{\circ} \mathrm{C} 1 \text { bar }\right)\end{array}$ & Zhang et al., 2015 \\
\hline
\end{tabular}

starting materials are mass-produced and low-cost and the whole fabrication process only involved three steps. The carbonization and inner-activation reaction occurred synchronously, and their combination effectively induced regional micropores. The removal of site-occupying templates ensured the formation of the interconnected micro-mesoporous structure built by ultrathin carbon walls. The well-developed micropore-enriched structure was further improved through the final post-activation process. The combination of nano- $\mathrm{CaCO}_{3}$ incorporation and carbon dioxide post-activation were found to have significant beneficial effects on the structural controllability, especially the microporosity and mesoporosity. The best structural property with t-plot micropore surface area of $786 \mathrm{~m}^{2} / \mathrm{g}$ and micropore volume of $0.320 \mathrm{~cm}^{3} / \mathrm{g}$ were translated into excellent carbon dioxide uptake of $2.84 \mathrm{mmol} / \mathrm{g}$ at $25^{\circ} \mathrm{C}$ and $3.66 \mathrm{mmol} / \mathrm{g}$ at $0^{\circ} \mathrm{C}$. Overall, the proposed synthesis methodology of HPCs looks promising for future applications in the field of carbon dioxide catalytic conversion.

\section{REFERENCES}

Ahmad, N. A., Leo, C. P., Ahmad, A. L., and Mohammad, A. W. (2016). Separation of $\mathrm{CO}_{2}$ from hydrogen using membrane gas absorption with PVDF/PBI membrane. Int. J. Hydrogen Energy 41, 4855-4861. doi: 10.1016/j.ijhydene.2015.11.054

Brunauer, S., Emmett, P. H., and Teller, E. (1938). Adsorption of gases in multimolecular layers. J. Am. Chem. Soc. 60, 309-319. doi: 10.1021/ja 01269a023

Chen, H., Zhang, S., Zhao, Z., Liu, M., and Zhang, Q. (2019). Application of dopamine functional materials in water pollution control. Prog. Chem. 31, 571-579. doi: 10.7536/PC180823

Dassanayake, R. S., Gunathilake, C., Dassanayake, A. C., Abidi, N., and Jaroniec, M. (2017). Amidoxime-functionalized nanocrystalline cellulose-mesoporous silica

\section{DATA AVAILABILITY STATEMENT}

All datasets generated for this study are included in the manuscript.

\section{AUTHOR CONTRIBUTIONS}

LH was the most important contributor of manuscript, and other authors have made a lot of contributions in experiments and writing of manuscript.

\section{FUNDING}

This work was supported by the National Natural Science Foundation of China (51504133), the Project of Liaoning Science and Technology Agency (20170540465) and the 2019 Project of Liaoning Education Department (2019LNJC20).

composites for carbon dioxide sorption at ambient and elevated temperatures. J. Mater. Chem. A 5, 7462-7473. doi: 10.1039/C7TA01038A

Fan, X., Zhang, L., Zhang, G., Shu, Z., and Shi, J. (2013). Chitosan derived nitrogendoped microporous carbons for high performance $\mathrm{CO}_{2}$ capture. Carbon 61, 423-430. doi: 10.1016/j.carbon.2013.05.026

Feng, S., Li, W., Shi, Q., Li, Y., Chen, J., Ling, Y., et al. (2014). Synthesis of nitrogen-doped hollow carbon nanospheres for $\mathrm{CO}_{2}$ capture. Chem. Commun. 50, 329-331. doi: 10.1039/C3CC46492J

Garbarino, G., Riani, P., Magistri, L., and Busca, G. (2014). A study of the methanation of carbon dioxide on $\mathrm{Ni} / \mathrm{Al}_{2} \mathrm{O}_{3}$ catalysts at atmospheric pressure. Int. J. Hydrogen Energy 39, 11557-11565. doi: 10.1016/j.ijhydene.2014.05.111

Günther, D., Beckmann, J., Schöneich, M., Schmidt, P., and Klepel, O. (2012). Porous concrete as a template for the synthesis of porous carbon materials. Carbon 50, 3096-3098. doi: 10.1016/j.carbon.2012.02.039 
Han, J. H., Ryu, J. H., and Lee, I. B. (2012). A preliminary infrastructure design to use fossil fuels with carbon capture and storage and renewable energy systems. Int. J. Hydrogen Energy 37, 17321-17335. doi: 10.1016/j.ijhydene.2012.08.117

Hao, G. P., Li, W. C., Qian, D., and Lu, A. H. (2010). Rapid synthesis of nitrogendoped porous carbon monolith for $\mathrm{CO}_{2}$ capture. Adv. Mater. 22, 853-857. doi: 10.1002/adma.200903765

Hayat, A., Rahman, M. U., Khan, I., Khan, J., Sohail, M., Yasmeen, H., et al. (2019). Conjugated electron donor-acceptor hybrid polymeric carbon nitride as a photocatalyst for $\mathrm{CO}_{2}$ reduction. Molecules 24:1779. doi: 10.3390/molecules24091779

Huang, K., Chai, S. H., Mayes, R. T., Tan, S., Jones, C. W., and Dai, S. (2016). Significantly increasing porosity of mesoporous carbon by $\mathrm{NaNH}_{2}$ activation for enhanced $\mathrm{CO}_{2}$ adsorption. Micropor. Mesopor. Mat. 230, 100-108. doi: 10.1016/j.micromeso.2016.04.041

Kanki, K., Maki, H., and Mizuhata, M. (2016). Carbon dioxide absorption behavior of surface-modified lithium orthosilicate/potassium carbonate prepared by ballmilling. Int. J. Hydrogen Energy 41, 18893-18899. doi: 10.1016/j.ijhydene.2016.06.158

Kim, P., Kim, H., Joo, J. B., Kim, W., Song, I. K., and Yi, J. (2005). Preparation and application of nanoporous carbon templated by silica particle for use as a catalyst support for direct methanol fuel cell. J. Power Sources 145, 139-146. doi: 10.1016/j.jpowsour.2005.01.070

Lavoie, J. M. (2014). Review on dry reforming of methane, a potentially more environmentally-friendly approach to the increasing natural gas exploitation. Front. Chem. 2:81. doi: 10.3389/fchem.2014.00081

Lee, S. Y., Jang, D. I., Bae, S. T., and Park, S. J. (2014). Facile synthesis of nitrogenenriched mesoporous carbon for carbon dioxide capture. Int. J. Hydrogen Energy 39, 12347-12352. doi: 10.1016/j.ijhydene.2014.03.086

Li, D., Chen, Y., Zheng, M., Zhao, H., Zhao, Y., and Sun, Z. (2016). Hierarchically structured porous nitrogen-doped carbon for highly selective $\mathrm{CO}_{2}$ capture. ACS Sustainable Chem. Eng. 4, 298-304. doi: 10.1021/acssuschemeng.5b01230

Li, T., Yang, G., Wang, J., Zhou, Y., and Han, H. (2013). Excellent electrochemical performance of nitrogen-enriched hierarchical porous carbon electrodes prepared using nano- $\mathrm{CaCO}_{3}$ as template. J. Solid State Electr. 17, 2651-2660. doi: 10.1007/s10008-013-2167-3

Li, X., Yu, J., Jaroniec, M., and Chen, X. (2019). Cocatalysts for selective photoreduction of $\mathrm{CO}_{2}$ into solar fuels. Chem. Rev. 119, 3962-4179. doi: $10.1021 /$ acs.chemrev.8b00400

Li, Y., Ben, T., Zhang, B., Fu, Y., and Qiu, S. (2013). Ultrahigh gas storage both at low and high pressures in $\mathrm{KOH}$-activated carbonized porous aromatic frameworks. Sci. Rep. 3:2420. doi: 10.1038/srep02420

Liang, Y., Harrison, D. P., Gupta, R. P., Green, D. A., and McMichael, W. J. (2004). Carbon dioxide capture using dry sodium-based sorbents. Energy Fuels 18, 569-575. doi: 10.1021/ef030158f

Liou, T. H. (2010). Development of mesoporous structure and high adsorption capacity of biomass-based activated carbon by phosphoric acid and zinc chloride activation. Chem. Eng. J. 158, 129-142. doi: 10.1016/j.cej.2009.12.016

Liu, B., Shioyama, H., Jiang, H., Zhang, X., and Xu, Q. (2010). Metalorganic framework (MOF) as a template for syntheses of nanoporous carbons as electrode materials for supercapacitor. Carbon 48, 456-463. doi: 10.1016/j.carbon.2009.09.061

Liu, H., Cao, C. Y., Wei, F. F., Jiang, Y., Sun, Y. B., Huang, P. P., et al. (2013). Fabrication of macroporous/mesoporous carbon nanofiber using $\mathrm{CaCO}_{3}$ nanoparticles as dual purpose template and its application as catalyst support. J. Phys. Chem. C 117, 21426-21432. doi: 10.1021/jp4078807

Lu, C., Bai, H., Wu, B., Su, F., and Hwang, J. F. (2008). Comparative study of $\mathrm{CO}_{2}$ capture by carbon nanotubes, activated carbons, and zeolites. Energy Fuels 22, 3050-3056. doi: 10.1021/ef8000086

Mahurin, S. M., Górka, J., Nelson, K. M., Mayes, R. T., and Dai, S. (2014). Enhanced $\mathrm{CO}_{2} / \mathrm{N}_{2}$ selectivity in amidoxime-modified porous carbon. Carbon 67, 457-464. doi: 10.1016/j.carbon.2013.10.018

Marszewska, J., and Jaroniec, M. (2017). Tailoring porosity in carbon spheres for fast carbon dioxide adsorption. J. Colloid Interf. Sci. 487, 162-174. doi: 10.1016/j.jcis.2016.10.033

Megías-Sayago, C., Bingre, R., Huang, L., Lutzweiler, G., Wang, Q., and Louis, B. (2019). $\mathrm{CO}_{2}$ adsorption capacities in zeolites and layered double hydroxide materials. Front. Chem. 7:551. doi: 10.3389/fchem.2019.00551
Meng, L. Y., and Park, S. J. (2012). Influence of MgO template on carbon dioxide adsorption of cation exchange resin-based nanoporous carbon. J. Colloid Interf. Sci. 366, 125-129. doi: 10.1016/j.jcis.2011.09.019

Patel, H. A., Byun, J., and Yavuz, C. T. (2017). Carbon dioxide capture adsorbents: chemistry and methods. ChemSusChem 10, 1303-1317. doi: $10.1002 /$ cssc. 201601545

Patiño, J., Gutiérrez, M. C., Carriazo, D., Ania, C. O., Fierro, J. L. G., Ferrer, M. L., et al. (2014). DES assisted synthesis of hierarchical nitrogen-doped carbon molecular sieves for selective $\mathrm{CO}_{2}$ versus $\mathrm{N}_{2}$ adsorption. J. Mater. Chem. A 2, 8719-8729. doi: 10.1039/C4TA00562G

Pullar, R. C., Novais, R. M., Caetano, A. P. F., Barreiros, M. A., Abanades, S., and Oliveira, F. A. C. (2019). A review of solar thermochemical $\mathrm{CO}_{2}$ splitting using ceria-based ceramics with designed morphologies and microstructures. Front. Chem. 7:601. doi: 10.3389/fchem.2019.00601

Qi, K., Cheng, B., Yu, J., and Ho, W. (2017). A review on $\mathrm{TiO}_{2}$ based Z-scheme photocatalysts. Chin. J. Catal. 38, 1936-1955. doi: 10.1016/S1872-2067(17)62962-0

Qi, K., Xie, Y., Wang, R., Liu, S., and Zhao, Z. (2019). Electroless plating Ni-P cocatalyst decorated g- $\mathrm{C}_{3} \mathrm{~N}_{4}$ with enhanced photocatalytic water splitting for $\mathrm{H}_{2}$ generation. Appl. Surf. Sci. 466, 847-853. doi: 10.1016/j.apsusc.2018.10.037

Santis, A. D., Ingham, D. B., Ma, L., and Pourkashanian, M. (2016). CFD analysis of exhaust gas recirculation in a micro gas turbine combustor for $\mathrm{CO}_{2}$ capture. Fuel 173, 146-154. doi: 10.1016/j.fuel.2016.01.063

Shi, W., Xu, X., Ye, C., Sha, D., Yin, R., Shen, X., et al. (2019). Bimetallic metal-organic framework-derived carbon nanotube-based frameworks for enhanced capacitive deionization and $\mathrm{Zn}$-air battery. Front. Chem. 7:449. doi: $10.3389 /$ fchem.2019.00449

Sing, K. S. W. (1985). Reporting physisorption data for gas/solid systems with special reference to the determination of surface area and porosity (Recommendations 1984). Pure Appl. Chem. 57, 603-619. doi: 10.1351/pac198557040603

Son, I. H., Lee, S. J., and Roh, H. S. (2014). Hydrogen production from carbon dioxide reforming of methane over highly active and stable $\mathrm{MgO}$ promoted $\mathrm{Co}-\mathrm{Ni} / \gamma-\mathrm{Al}_{2} \mathrm{O}_{3}$ catalyst. Int. J. Hydrogen Energy 39, 3762-3770. doi: 10.1016/j.ijhydene.2013.12.141

Song, H., Liu, Z., Gai, H., Wang, Y., Qiao, L., Zhong, C., et al. (2019). Nitrogendopped ordered mesoporous carbon anchored Pd nanoparticles for solvent free selective oxidation of benzyl alcohol to benzaldehyde by using $\mathrm{O}_{2}$. Front. Chem. 7:458. doi: $10.3389 /$ fchem.2019.00458

Sun, Q., Yang, Y., Zhao, Z., Zhang, Q., Zhao, X., Nie, G., et al. (2018). Elaborate design of polymeric nanocomposites with $\mathrm{Mg}$ (ii)-buffering nanochannels for highly efficient and selective removal of heavy metals from water: case study for Cu(ii). Environ. Sci. Nano 5, 2440-2451. doi: 10.1039/C8EN00611C

Wang, W., Chu, W., Wang, N., Yang, W., and Jiang, C. (2016). Mesoporous nickel catalyst supported on multi-walled carbon nanotubes for carbon dioxide methanation. Int. J. Hydrogen Energy 41, 967-975. doi: $10.1016 /$ j.ijhydene.2015.11.133

Wei, J., Zhou, D., Sun, Z., Deng, Y., Xia, Y., and Zhao, D. (2013). A controllable synthesis of rich nitrogen-doped ordered mesoporous carbon for $\mathrm{CO}_{2}$ capture and supercapacitors. Adv. Funct. Mater. 23, 2322-2328. doi: 10.1002/adfm.201202764

Wickramaratne, N. P., and Jaroniec, M. (2013a). Activated carbon spheres for $\mathrm{CO}_{2}$ adsorption. ACS Appl. Mater. Interfaces 5, 1849-1855. doi: 10.1021/am400112m

Wickramaratne, N. P., and Jaroniec, M. (2013b). Importance of small micropores in $\mathrm{CO}_{2}$ capture by phenolic resin-based activated carbon spheres. J. Mater. Chem. A 1, 112-116. doi: 10.1039/C2TA00388K

Wu, X. L., Jiang, L. Y., Cao, F. F., Guo, Y. G., and Wan, L. J. (2009). $\mathrm{LiFePO}_{4}$ nanoparticles embedded in a nanoporous carbon matrix: superior cathode material for electrochemical energy-storage devices. Adv. Mater. 21, 2710-2714. doi: 10.1002/adma.200802998

Xia, K., Tian, X., Fei, S., and You, K. (2014). Hierarchical porous graphenebased carbons prepared by carbon dioxide activation and their gas adsorption properties. Int. J. Hydrogen Energy 39, 11047-11054. doi: 10.1016/j.ijhydene.2014.05.059

Xia, Y., Tian, Z., Heil, T., Meng, A., Cheng, B., Cao, S., et al. (2019). Highly selective $\mathrm{CO}_{2}$ capture and its direct photochemical conversion on ordered 2D/1D heterojunctions. Joule 3, 2792-2805. doi: 10.1016/j.joule.2019.08.011 
Xu, B., Shi, L., Guo, X., Peng, L., Wang, Z., Chen, S., et al. (2011). Nano- $\mathrm{CaCO}_{3}$ templated mesoporous carbon as anode material for Liion batteries. Electrochim. Acta 56, 6464-6468. doi: 10.1016/j.electacta.2011. 04.130

Xu, K., Pan, Q., Zheng, F., Zhong, G., Wang, C., Wu, S., et al. (2019). Hierarchical nitrogen-doped porous carbon microspheres as anode for high performance sodium ion batteries. Front. Chem. 7:733. doi: 10.3389/fchem. 2019.00733

Yaumi, A. L., Abu Bakar, M. Z., and Hameed, B. H. (2017). Recent advances in functionalized composite solid materials for carbon dioxide capture. Energy 124, 461-480. doi: 10.1016/j.energy.2017.02.053

Zhang, Q., Bolisetty, S., Cao, Y., Handschin, S., Adamcik, J., Peng, Q., et al. (2019). Selective and efficient removal of fluoride from water: in situ engineered amyloid fibril/ $\mathrm{ZrO}_{2}$ hybrid membranes. Angew. Chem. Int. Ed. 58, 6012-6016. doi: 10.1002/anie.201901596

Zhang, Z., Wang, B., Zhu, C., Gao, P., Tang, Z., Sun, N., et al. (2015). Facile onepot synthesis of mesoporous carbon and $\mathrm{N}$-doped carbon for $\mathrm{CO}_{2}$ capture by a novel melting-assisted solvent-free method. J. Mater. Chem. A 3, 23990-23999. doi: 10.1039/C5TA06465A

Zhao, C., Wang, W., Yu, Z., Zhang, H., Wang, A., and Yang, Y. (2010). Nano$\mathrm{CaCO}_{3}$ as template for preparation of disordered large mesoporous carbon with hierarchical porosities. J. Mater. Chem. 20, 976-980. doi: 10.1039/B 911913B

Zhu, B., Wageh, S., Al-Ghamdi, A. A., Yang, S., Tian, Z., and Yu, J. (2019). Adsorption of $\mathrm{CO}_{2}, \mathrm{O}_{2}, \mathrm{NO}$ and $\mathrm{CO}$ on s-triazine-based g$\mathrm{C}_{3} \mathrm{~N}_{4}$ surface. Catalysis Tdy. 335, 117-127. doi: 10.1016/j.cattod.2018. 09.038

Zhu, Q., Zeng, S., and Yu, Y. (2017). A model to stabilize $\mathrm{CO}_{2}$ uptake capacity during carbonation-calcination cycles and its case of CaO-MgO. Environ. Sci. Technol. 51, 552-559. doi: 10.1021/acs.est.6b04100

Conflict of Interest: The authors declare that the research was conducted in the absence of any commercial or financial relationships that could be construed as a potential conflict of interest.

Copyright (c) 2020 Zhang, Wang, Luo, Lu, Peng, Wang and Han. This is an openaccess article distributed under the terms of the Creative Commons Attribution License (CC BY). The use, distribution or reproduction in other forums is permitted, provided the original author(s) and the copyright owner(s) are credited and that the original publication in this journal is cited, in accordance with accepted academic practice. No use, distribution or reproduction is permitted which does not comply with these terms. 